\title{
Physiological and biochemical responses of Eucalyptus seedlings to hypoxia
}

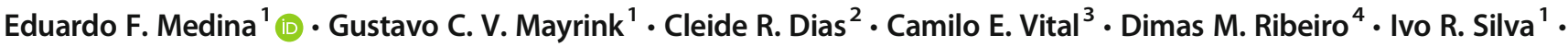 \\ Andrew Merchant ${ }^{5}$
}

Received: 2 June 2018 / Accepted: 4 December 2018 / Published online: 7 January 2019

(C) INRA and Springer-Verlag France SAS, part of Springer Nature 2019

\begin{abstract}
- Key message Hypoxia promoted distinct changes in the levels of hormones, amino acids and organic acids in the roots and shoots of a seedling from 2 Eucalyptus clones. These results indicate that modulation of hormone production, as well as specific chemical constituents associated with primary metabolism, contributes to the regulation of growth of Eucalyptus seedlings under hypoxic conditions.

- Context Although floods in areas under Eucalyptus cultivation in Brazil negatively affect plant growth, chemical markers and/ or indicators of hypoxia contributes to the regulation.s

- Aims This study aimed to evaluate the hormonal and metabolic alterations induced by hypoxia on seedling growth.

- Methods Seedlings of Eucalyptus urograndis clones VCC 975 and 1004 were grown in liquid solution and submitted to bubbling with air or with nitrogen. Levels of indol-3-acetic acid (IAA), abscisic acid (ABA), ethylene, 1-aminocyclopropane1-carboxylic acid (ACC), primary metabolite profile and photosynthetic parameters were evaluated after fourteen days.

- Results Hypoxia did not affect shoot dry mass of the seedlings. However, it decreased stomatal conductance and photosynthetic $\mathrm{CO}_{2}$ assimilation rate, and increased levels of ABA in the shoot. Hypoxia greatly reduced the dry mass and volume of roots, concomitantly with higher ACC and ethylene production. Moreover, hypoxia promoted distinct changes in IAA levels, and in amino acid and organic acid metabolism in roots and shoots.

- Conclusion The biosynthesis of ABA, ethylene and IAA and its quantity in root tissues indicates the regulation of metabolism in response to hypoxia in Eucalyptus clones.
\end{abstract}

Handling Editor: Erwin Dreyer

\section{Contribution of the co-authors:}

EFM designed, executed the study, and was the main contributor to the writing of the manuscript. Gustavo CV MAYRINK and Cleide R DIAS contributed to maintaining and completing the experiment. Camilo $\mathrm{E}$ VITAL performed the LC-MS analysis. Dimas M RIBEIRO, Ivo R SILVA, and Andrew MERCHANT assisted in the design of the experiment, analysis of the results and composition of the paper.

Electronic supplementary material The online version of this article (https://doi.org/10.1007/s13595-018-0789-4) contains supplementary material, which is available to authorized users.

Eduardo F. Medina

e.medinaufv@gmail.com

Gustavo C. V. Mayrink

gcventuram@hotmail.com

Cleide R. Dias

cleideufv@gmail.com

Camilo E. Vital

camiloelber@gmail.com
Dimas M. Ribeiro

dimas.ribeiro@ufv.br

Ivo R. Silva

ivosilvaufv@gmail.com

Andrew Merchant

andrew.merchant@sydney.edu.au

Extended author information available on the last page of the article 
Keywords Growth inhibition $\cdot$ Hormones $\cdot$ Photosynthetic response $\cdot$ Primary metabolism

\section{Introduction}

Eucalyptus plantations contribute significantly to the global economy, with around 6 million hectares planted in Brazil alone (ABRAF 2013). Eucalyptus wood is the basis for several bioenergy and industrial industries such as charcoal, engineered products, and pulp and paper (Rockwood et al. 2008). Furthermore, managed forest plantations provide wood production for various industries helping to preserve the native forests from logging (IBA 2014). However, significant losses of timber caused by elevated rainfall periods have been reported across Brazilian Cerrado regions with planted eucalypts (Leite et al. 2014; Gonçalves et al. 2016).

Short-term hypoxia is likely to increase across South America, particularly on compacted and/or soils with shallow profiles $(40-50 \mathrm{~cm}$ deep) where drainage is blocked. This results from changes in rainfall seasonality and the increase of rainfall under climate change (Harguindeguy et al. 2017; Gonçalves et al. 2016; Feng et al. 2013). Plant tolerance to hypoxia is a result of morphological and physiological adaptations (Kreuzwieser and Rennenberg 2014). Morphological changes in the roots are usually preceded by changes in the leaves such as stomatal closure as well as a reduction in photosynthesis and transpiration (Beckman et al. 1992; Bailey-Serres and Voesenek 2008; Voesenek and Bailey-Serres 2015). As a consequence of waterlogging, roots are exposed to internal variations in $\mathrm{O}_{2}$ (hypoxia or anoxia in severe situations) and $\mathrm{CO}_{2}$ concentrations, as well as increased ethylene and reactive oxygen species (Steffens et al. 2013; Yamauchi et al. 2013). Ethylene biosynthesis and systems modified by ethylene have been shown to be involved closely with hypoxia stress responses (Cao et al. 2007; Pierik et al. 2007). For example, the ability to produce adventitious roots is commonly associated with enhanced tolerance to hypoxia and their development has commonly been associated with ethylene production and perception (Voesenek et al. 1993; Mergemann and Sauter 2000; Steffens and Rasmussen 2016). However, ethyleneregulated processes interact with events controlled by other hormones, including abscisic acid, gibberellins, and auxin to control growth under hypoxia conditions (Steffens and Sauter 2009). Hypoxia also induces changes in the energy metabolism in plants (Paul et al. 2016). Many reports indicate that hypoxia negatively impacts plant growth in Eucalyptus species. Despite the known role of plant hormones in governing plant responses to hypoxia, no study has previously sought to quantify fluctuations in hormone abundance during low $\mathrm{O}_{2}$ conditions to evaluate their use as indicators of stress or potential targets for breeding tolerant genotypes.

The growth and development of plants are influenced by carbon availability via tightly controlled reactions in close proximity to the primary photosynthetic reactions (Sulpice et al. 2014). This enables rapid feedback mechanisms to prevent damage to the highly sensitive photosynthetic apparatus. Plants in flooded soil often show a decreased net photosynthetic rate (Dreyer 1994; Kreuzwieser and Rennenberg 2014), which can significantly affect root carbohydrate metabolism (Colmer and Voesenek 2009). A decrease in stomatal conductance can be caused by reductions in root hydraulic conductance or from "signals" from the $\mathrm{O}_{2}$-deficient roots (Vartapetian and Jackson 1997; Argus et al. 2015). In this context, the precise nature of potential signaling compounds responsible for stomatal closure remains unresolved (Kreuzwieser and Rennenberg 2014). The involvement of 1-aminocyclopropane-1-carboxylic acid (ACC) and abscisic acid (ABA) as a root-derived signal has been proposed (Bai et al. 2011). However, low- $\mathrm{O}_{2}$ responses vary widely depending on the plant species, genotype, and stage of development (Voesenek and Bailey-Serres 2015). It is known that seedlings are particularly vulnerable to carbohydrate starvation (Graf et al. 2010).

Intra-specific variation in tolerance to hypoxia is observed among clones of Eucalyptus, particularly within the hybrid E. urograndis (a hybrid between E. urophylla and E. grandis) (Harguindeguy et al. 2017). Despite this occurrence, the physiological and/or chemical basis for this variation is not known. A key question is, therefore, how Eucalyptus seedlings can acclimate to decreased $\mathrm{O}_{2}$ in the rhizosphere. Plant responses to hypoxia are typically multifaceted (see for example Loreti et al. 2016), it is, therefore, necessary to concurrently screen compound classes implicated in hypoxia responses on a background of physiological characterization. Here, a physiological analysis of Eucalyptus clones growing under a low $\mathrm{O}_{2}$ regime in the root-zone is combined with the quantification of the major hormones as well as shoot and root metabolite profiling to evaluate the role of primary metabolism and plant hormones in controlling the growth responses to low $\mathrm{O}_{2}$ concentration. We expect that the imposition of hypoxic conditions will: (1) induce differential responses in physiological activity between two Eucalyptus clones, (2) elicit changes in the abundance and distribution of measured hormones in roots and shoots and, (3) induce differential changes in the TCA cycle manifested through changes in the abundance of selected amino acids in the two clones. 


\section{Material and methods}

\subsection{Plant material and growth conditions}

Seedlings of two Eucalyptus clones (VCC 975 and VCC 1004) were obtained from Veracel Cellulose S.A. (Eunápolis, BA, Brazil). The clones are characterized as Eucalyptus urograndis obtained by controlled a crosspollination between Eucalyptus grandis W. Hill ex Maiden and Eucalyptus urophylla S. T. Blake (details about Eucalyptus clones can be found on the National Register of Cultivars Website). Clone VCC 975 and clone VCC 1004 are two of the most widespread genotypes planted in Brazil and selected based on wood volume, density, and cellulose production (Bison et al. 2006). Clone VCC 975 is considered tolerant and clone VCC 1004 sensitive to $\mathrm{O}_{2}$ depletion during high rainfall periods (Fig. S2) (http://sistemas.agricultura.gov. $\mathrm{br} / \mathrm{snpc} /$ cultivarweb/cultivares_registradas.php). Seedlings were cultivated in a greenhouse at the Universidade Federal de Viçosa $\left(20^{\circ} 45^{\prime} \mathrm{S}, 42^{\circ} 15^{\prime} \mathrm{W}, 650 \mathrm{~m}\right.$ altitude) in southeastern Brazil under natural light and temperature (Fig. S1). Seedlings were first established by growth in small tubes with topsoil for 1 month. Afterwards, seedlings were acclimated to the nutrient solution before the beginning of the experiment. During the acclimation period, seedlings were grown in plastic pots with an 8-L capacity containing Clark's solution with $12.5 \%$ of its normal concentration for 7 days (Clark 1975). During the second week, the concentration used was $25 \%$ of the normal concentration of Clark's solution. After the third week, the plants were kept in Clark's solution with 50\% of its normal concentration until the end of the experiment. Three weeks after transferring seedlings to the pots, the air was bubbled through the solution until a maximum concentration of $8 \mathrm{mg} / \mathrm{L}$ of dissolved oxygen was achieved (control treatment) as measured by an AT 170 oximeter (Alfakit LTDA, Florianópolis, SC, BR). For the hypoxia treatment, nitrogen gas ( $>99.95 \%$ pure) was bubbled through the solution until the concentration of dissolved oxygen decreased to $4 \mathrm{mg} / \mathrm{L}$. Both control and treatment oxygen levels were maintained throughout the course of the experiment. The experimental design consisted of 24 individual trees (12 of each genotype) each allocated to either treatment or control pots. Three trees were housed per pot with eight pots in total. Pots were randomized periodically to minimize any variation within the greenhouse.

\subsection{Determination of damage to shoot and root}

Seedlings were harvested and separated into the shoot and root 14 days after the imposition of hypoxia. Root volume was measured by the water volume displaced in a clear graduated cylinder as described by Harrington et al. (1994). Afterwards, the shoot and root of each seedling were oven-dried for at least
3 days at $70^{\circ} \mathrm{C}$ and dry mass was determined. Photographs of the root tips of all treatments were taken on the stereoscopic microscope Zeiss Stemi 2000-C 5 days after imposing treatments in order to visualize damage to root tips (black zones).

\subsection{Determination of ethylene levels}

Ethylene was measured from whole roots with approximately $2 \mathrm{~g}$ of fresh mass. Excised roots were allowed to recover for $30 \mathrm{~min}$ prior to collecting ethylene as described by GeislerLee et al. (2010). Roots were placed in glass flasks $(750 \mathrm{~mL})$ containing $4 \mathrm{~mL}$ of deionized water to maintain hydration of the roots and the flasks capped with a rubber septum. The atmosphere of the flask was mixed occasionally with a long needle syringe. Following an 18 -h incubation, a sample of $1 \mathrm{~mL}$ was taken from the flask headspace with a syringe and the ethylene concentration was measured by gas chromatography as described by Silva et al. (2014).

\subsection{Measurements of photosynthetic parameters}

Chlorophyll fluorescence in fully expanded leaves was measured with a Pulse Amplitude Modulated fluorometer integrated in a photosynthesis chamber (Li-Cor LI-6400XT). After acclimation of the leaves to the dark (for $30 \mathrm{~min}$ ), minimum $\left(\mathrm{F}_{0}\right)$, and maximum $\left(\mathrm{F}_{\mathrm{m}}\right)$ fluorescence were recorded to derive the $F_{v} / f m$ ratio. This ratio is a proxy of the potential photochemical efficiency of PSII (Genty et al. 1989). Net photosynthetic rate $(A)$, stomatal conductance to water vapor $\left(g_{\mathrm{s}}\right)$ and intercellular to ambient $\mathrm{CO}_{2}$ concentration ratios $\left(C_{\mathrm{i}} / C_{\mathrm{a}}\right)$ were determined in fully expanded leaves, using a $\mathrm{Li}-6400$ open gas exchange system (Li-Cor, Lincoln, NE, USA) equipped with a blue/red light source (Li-6400-02B). Measurements were taken between 08:00 $\mathrm{h}$ and 12:00 $\mathrm{h}$ at an ambient temperature, air relative humidity, and $\mathrm{CO}_{2}$ conditions (about $23{ }^{\circ} \mathrm{C}, 81 \%$, and $390 \mathrm{ppm}$ respectively) under artificial light with $1400 \mu \mathrm{mol}$ photons $\mathrm{m}^{-2} \mathrm{~s}^{-1}$ at the leaf level and air flow of $300 \mu \mathrm{mol} \mathrm{s}^{-1}$ through the chamber.

\subsection{Measurement of hormones}

Hormones were extracted from the Eucalyptus leaves and roots following the methods described by Müller and Munné-Bosch (2011) with modifications. Approximately, $110 \mathrm{mg}$ of fresh tissue was powdered in liquid nitrogen with $400 \mu \mathrm{l}$ of extraction solvents added (methanol: isopropyl alcohol: acetic acid, 20: 79: 1). The samples were mixed in the vortex (four times for $20 \mathrm{~s}$ ), sonicated ( $5 \mathrm{~min}$ ), and kept on ice (30 min). After centrifugation $\left(13,000 \mathrm{~g}, 10 \mathrm{~min}\right.$ in $4{ }^{\circ} \mathrm{C}$ ), $350 \mu \mathrm{l}$ supernatant was removed and put in a new tube. The process was repeated with the pellet resultant and then the supernatants were pooled. A last centrifugation $(20,000 \mathrm{~g}$, $10 \mathrm{~min}$ in $4{ }^{\circ} \mathrm{C}$ ) was made to remove the rest of the tissue in 
suspension. The sample was automatically injected $(5 \mu \mathrm{l})$ in the LC-MS/MS using an Agilent 1200 Infinity Series coupled to a mass spectrometry with a triple Quadrupole (QqQ), model 6430 Agilent Technologies. Chromatographic separation was carried out on a column Zorbax Eclipse Plus C18 $(1.8 \mu \mathrm{m}$, $2.1 \times 50 \mathrm{~mm}$ ) (Agilent) in series with a guard column Zorbax SB-C18, $1.8 \mu \mathrm{m}$ (Agilent). The solvent used was: (A) acetic acid $0.02 \%$ in water and (B) acetic acid $0.02 \%$ in acetonitrile in a gradient of time $/ \% \mathrm{~B}: 0 / 5 ; 11 / 60 ; 13 / 95 ; 17 / 95 ; 19 / 5 ; 20 / 5$. The solvent flow rate was $0.3 \mathrm{ml} / \mathrm{min}$ in a column temperature of $30^{\circ} \mathrm{C}$. Ionization used was an ESI (electrospray ionization) with the following conditions: gas temperature of $300^{\circ} \mathrm{C}$, the nitrogen flow rate of $10 \mathrm{~L} / \mathrm{min}$, nebulizer pressure of $35 \mathrm{psi}$, and a capillary voltage of $4000 \mathrm{~V}$. The equipment was operated in MRM mode (multiple reaction monitoring). The mass of the precursor ion/fragment established was monitored by fragmentation tests of each molecule: ethylene precursor ACC (102.1/56.2), ABA (263/153) and IAA (176/130). A calibration curve $(0.1$ to $200 \mathrm{ng})$ using the respective standards of each hormone was generated to determine the absolute quantification. The generated data were analyzed in the software "MassHunter Workstation" to obtain the peak areas for each hormone in the sample and the results were expressed in nanogram/gram of fresh tissue.

\subsection{Metabolite analyses}

After metabolite extraction, a gas chromatography-mass spectrometry (GC-MS)-based metabolite profile was performed as described by Lisec et al. (2006). Briefly, leaf and root tissue $(100 \mathrm{mg})$ were homogenized with liquid nitrogen and extracted in $1.4 \mathrm{~mL}$ methanol, and $60 \mu \mathrm{L}$ internal standard $(0.2 \mathrm{mg}$ ribitol $\mathrm{mL}^{-1}$ water) was subsequently added as a quantification standard. The mixture was extracted for $15 \mathrm{~min}$ at $70{ }^{\circ} \mathrm{C}$ and mixed vigorously with $1.4 \mathrm{~mL}$ water. To separate polar and nonpolar metabolites, $750 \mu \mathrm{L}$ of chloroform was then added. After centrifugation at $2200 \mathrm{~g}$, the upper methanol/ water phase was taken and reduced to dryness in a vacuum. Residues were redissolved and derivatized in $40 \mu \mathrm{l}$ of $20 \mathrm{mg} \mathrm{mL}{ }^{-1}$ methoxyamine hydrochloride in pyridine at $37^{\circ} \mathrm{C}$ for $120 \mathrm{~min}$. Afterwards, the extract was treated with $60 \mu 1 \mathrm{~N}$-methyl- $N$-[trimethylsilyl] trifluoroacetamide at $37^{\circ} \mathrm{C}$, for $30 \mathrm{~min}$. Eight microliters of a retention time standard mixture $(0.029 \%[v / v] n$-dodecane, $n$-pentadecane, $n$-nonadecane, $n$-docosane, $n$-octacosane, $n$-dotracontane, and $n$ hexatriacontane dissolved in anhydrous pyridine) was added before trimethylsilylation. Sample volumes of $1 \mu \mathrm{L}$ were then injected in the GC-MS system AOC-20i autosampler, and a QP2010 SE gas chromatograph-quadrupole mass spectrometer (Shimadzu, Tokyo, Japan), equipped with a column Rtx5MS (Restek, Bellefonte, CA, USA). The derivatization, standard addition, and sample injection steps were carried out exactly as previously described (Lisec et al. 2006). Both chromatograms and mass spectra were evaluated using TAGFINDER software (Luedemann et al. 2008). Compounds were identified according to standardized guidelines (Dethloff et al. 2014) by mass spectral and retention time index matching to the mass spectral collection of the NIST11 database. Laboratory and reagent contaminations were identified by non-sample control experiments and removed from further analysis. Numerical analyses were based on the peak height values of the recoded mass feature, i.e., the response values. These values were corrected for the dry weight of each sample and by the response of the internal standard from each respective GC-MS chromatogram to obtain normalized responses.

\subsection{Statistical analyses}

The experiment was designed in a randomized block (pot) distribution with two different clones, three plants per pot, two pots per treatment (control and hypoxia). For growth analysis, 24 seedlings were assayed. For the quantification of metabolites and hormones, three leaves were bulked (combined) from each plant and assayed. Similarly, three separate root samples were taken from each plant, bulked and assayed. This procedure led to one sample of leaf and one root from each plant in each pot. Leaf gas exchange and chlorophyll fluorescence parameters were obtained in ten independent replications. Data were statistically examined using analysis of variance. Difference between treatment means $(P<0.05)$ was assessed by Tukey. The $t$ test was used in a metabolic profile with the relative values. All the statistical analyses were performed using Action Stat for Windows statistical software (São Carlos, SP, Brazil). It was also performed with the two-way ANOVA (Supplementary material 2 ) with the absolute values of the metabolites in order to access the effects of the hypoxic treatment, the different clones, and the pots using the R Studio program (version 1.1.447 RStudio, Inc).

Statement on data availability The datasets generated during and/or analyzed during the current study are available from the corresponding author on reasonable request.

\section{Results}

Shoot dry mass did not display any change in response to the hypoxic condition in both Eucalyptus clones (Fig. 1a). Hypoxia reduced the rate of net photosynthesis $(A)$ by approximately $30 \%$ in the two clones compared with their respective controls (Fig. 1b). Furthermore, intracellular $\mathrm{CO}_{2}$ concentration $\left(C_{\mathrm{i}}\right)$ and intracellular-to-atmospheric $\mathrm{CO}_{2}$ ratio $\left(C_{\mathrm{i}} / C_{\mathrm{a}}\right)$ were unaltered in leaves of clone VCC 975 , but hypoxia led to a significant decrease of $C_{\mathrm{i}}$ and $C_{\mathrm{i}} / C_{\mathrm{a}}$ in the shoot of 
Fig. 1 Physiological impacts observed in Eucalyptus clones under hypoxic conditions. a Shoot dry mass. b Photosynthetic $\mathrm{CO}_{2}$ assimilation rate. c Intracellular $\mathrm{CO}_{2}$ concentration. d Intracellular-to-atmospheric $\mathrm{CO}_{2}$ ratio. e Variable-to-maximum chlorophyll fluorescence. $\mathbf{f}$ Stomatal conductance. Bars followed by the same letters do not differ statistically at the 5\% level by Tukey test. Values are presented as means of six replicates \pm standard error a
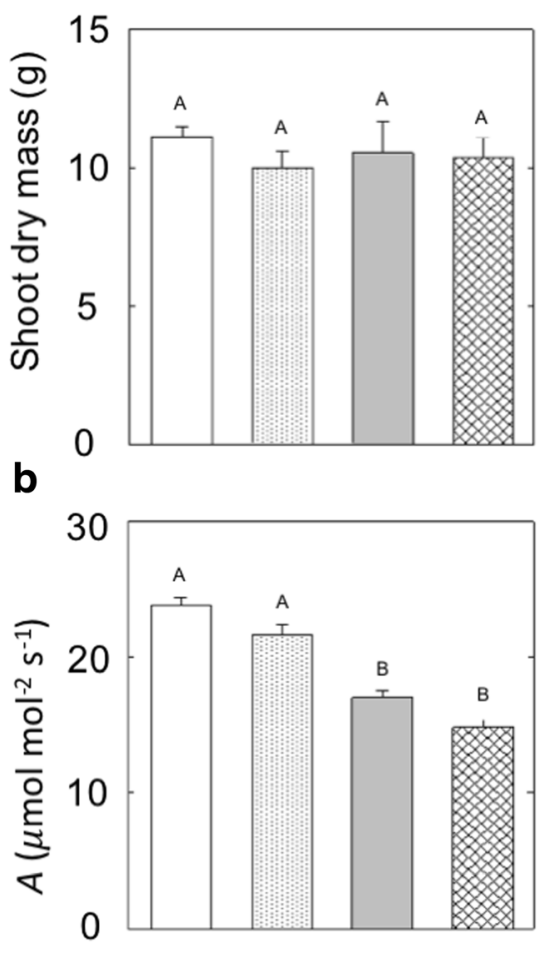

C

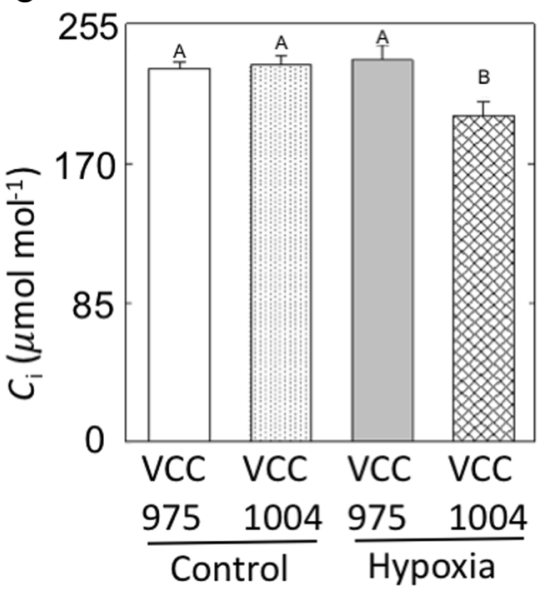

d

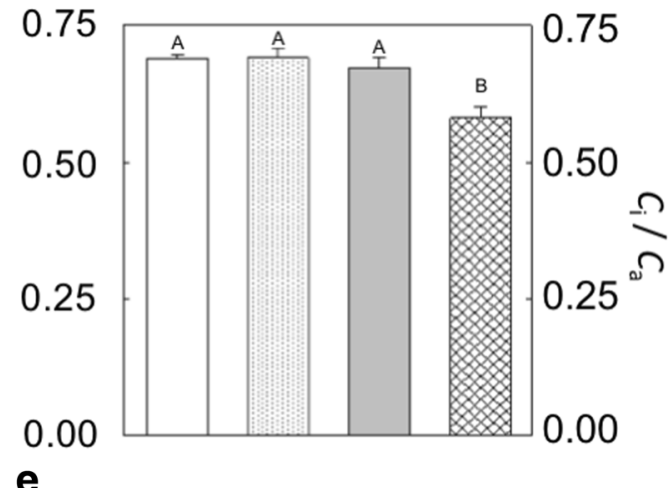

e

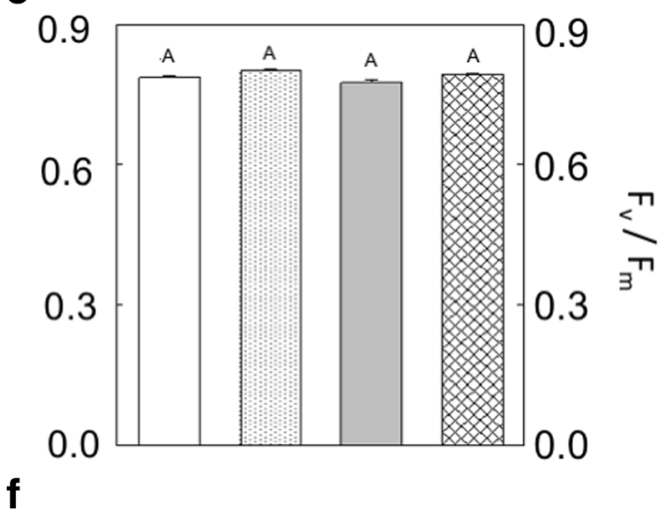

$\mathbf{f}$

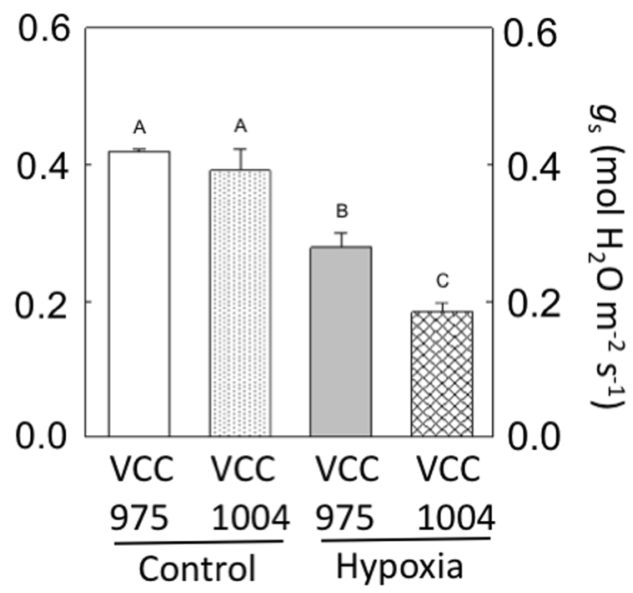

Eucalyptus clone VCC 1004 (Fig. 1c, d). The maximum photochemical efficiency of PSII $\left(F_{\mathrm{v}} / \mathrm{fm}\right)$ was not affected by hypoxia (Fig. 1e). The results also showed a decrease in the stomatal conductance $\left(g_{\mathrm{s}}\right)$ of 34 and $53 \%$, as compared with control, in seedlings of VCC 975 and VCC 1004 under hypoxia condition, respectively (Fig.1f).

For plant hormones in roots and shoots, an increase in the ABA levels of 175 and $150 \%$, was detected compared with control plants, in leaves of clone VCC 975 and VCC 1004 under the hypoxic condition, respectively (Fig. 2a). Levels of ACC were increased in shoots of clone VCC 1004, with no changes in the shoot of clone VCC 975 (Fig. 2b). In addition, the levels of indol-3-acetic acid (IAA) in shoots of the two clones were similar to those observed in control plants
(Fig. 2c). Five days after the onset of hypoxia, root tips turned black over 1-2 cm (Fig. 3a). Furthermore, hypoxia reduced root dry mass and root volume as compared with controls (Fig. 3b, c). The levels of IAA in the root decreased approximately fivefold for clone VCC 975 and twofold for clone VCC 1004 (Fig. 4a). By contrast to the situation observed for IAA, the levels of ACC and ethylene were strongly increased in the roots of the two clones, as compared with controls (Fig. 4b, c).

Minor changes in the levels of amino acids were observed in shoots of Eucalyptus clones under hypoxia (Fig. 5a). Alanine levels were increased $>2.2$-fold in the shoot of clone VCC 1004, with no change in the shoot of clone VCC 975 (Fig. 5a). By contrast, significant changes of amino acid levels 


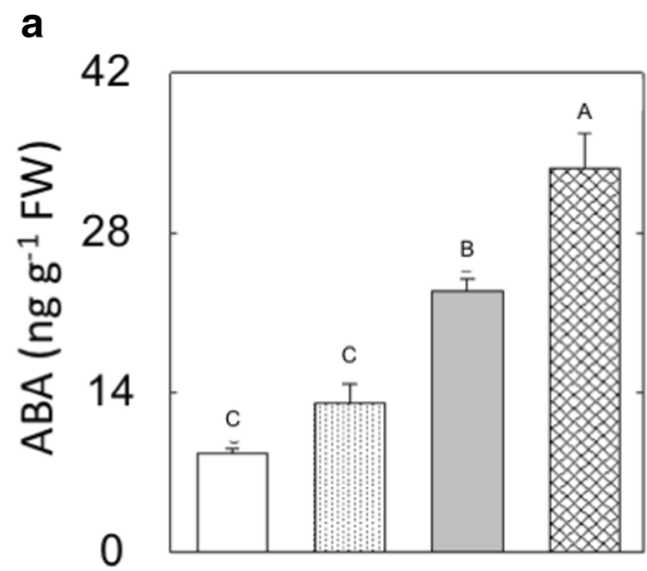

b

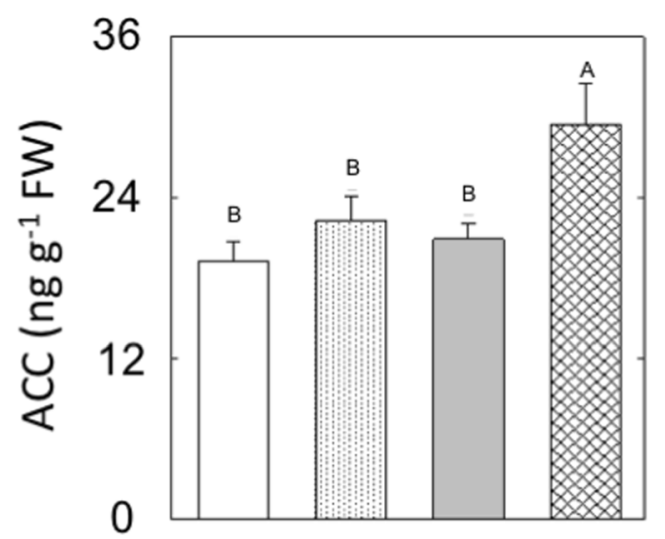

C

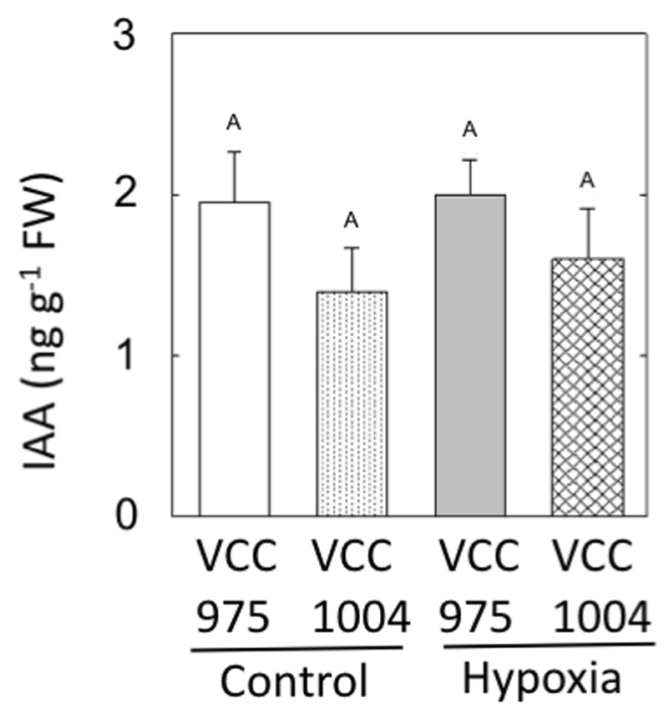

Fig. 2 Levels of a abscisic acid, b 1-aminocyclopropane-1-carboxylic acid, and $\mathbf{c}$ indol-3-acetic acid in shoot of Eucalyptus clones under hypoxic conditions. Bars followed by the same letters do not differ statistically at the $5 \%$ level by Tukey test. Values are presented as means of six replicates \pm standard error a

VCC 975

VCC 1004

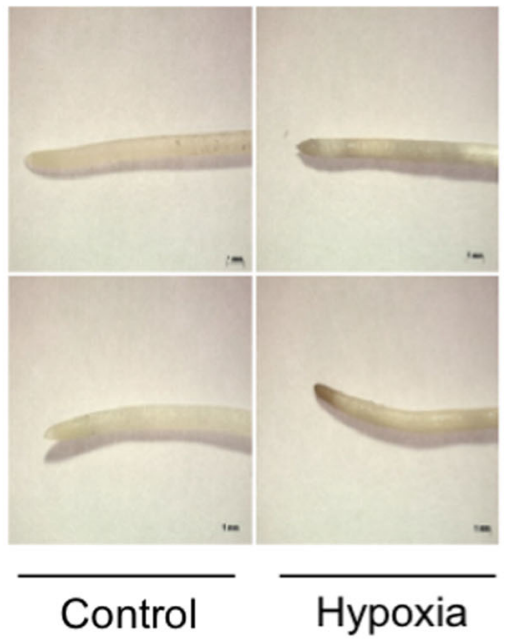

b

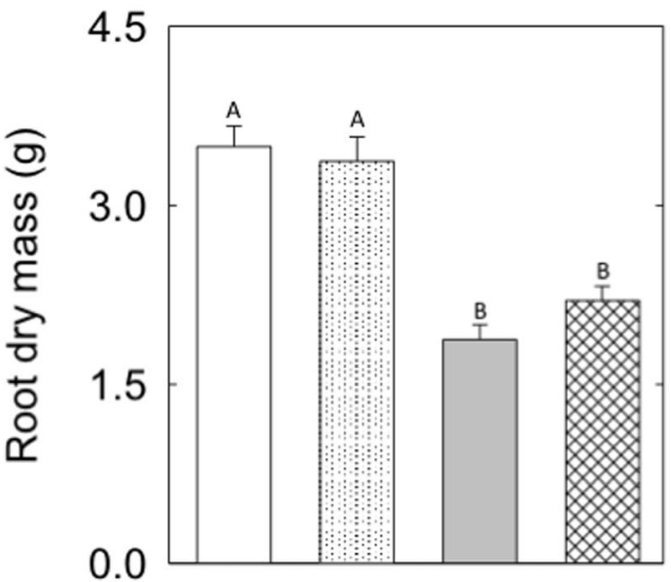

C

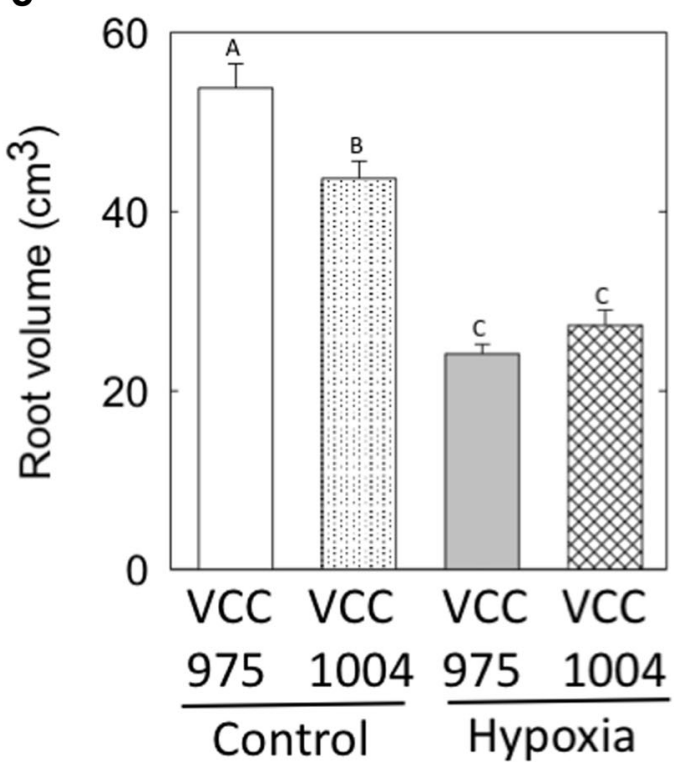

Fig. 3 Phenotypic changes of root of Eucalyptus clones caused by hypoxic conditions. a Photography of root cross sections. b Root dry mass. c Root volume. Bars followed by the same letters do not differ statistically at the $5 \%$ level by Tukey test. Values are presented as means of six replicates \pm standard error 
a

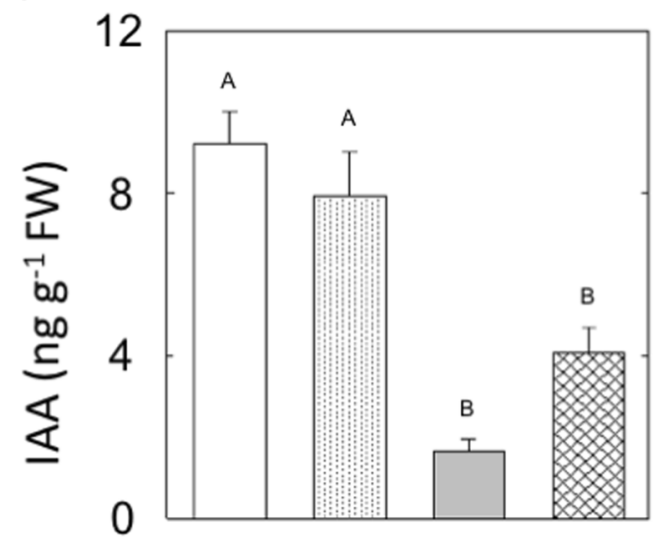

b

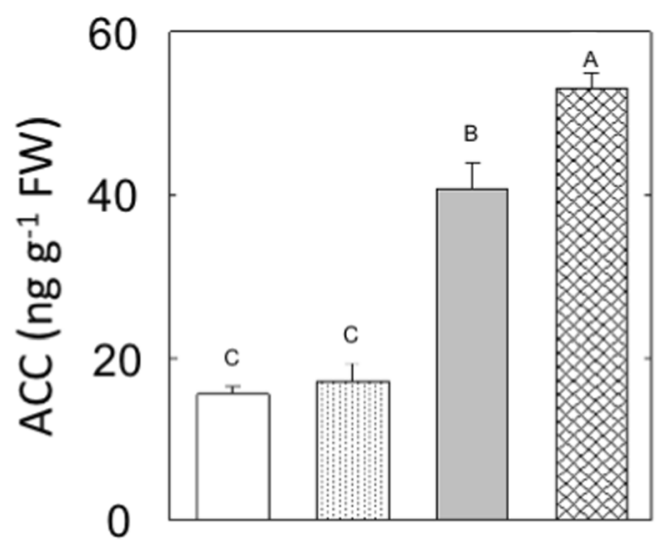

C

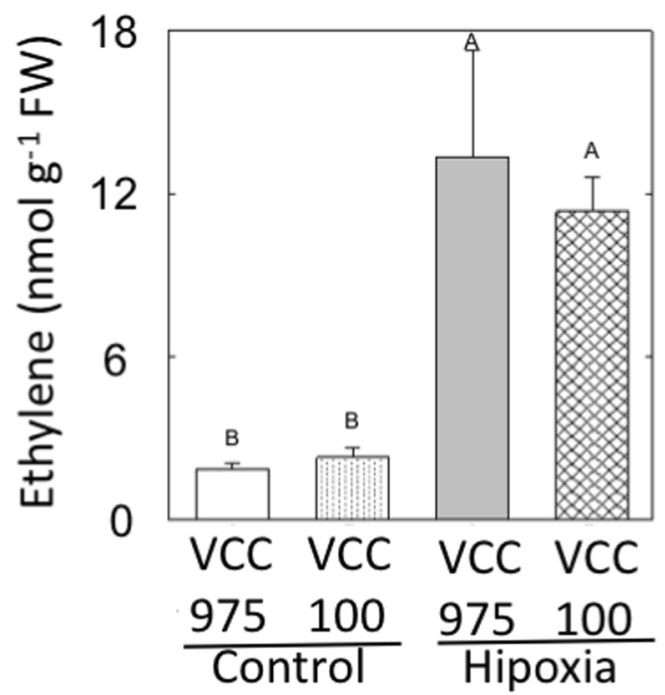

Fig. 4 Levels of a indol-3-acetic acid, b 1-aminocyclopropane-1carboxylic acid, and $\mathbf{c}$ ethylene in the root of Eucalyptus clones under hypoxic conditions. Bars followed by the same letters do not differ statistically at the $5 \%$ level by Tukey test. Values are presented as means of six replicates \pm standard error were observed in roots of the two clones under hypoxia (Fig. 5b). Roots of clone VCC 975 and VCC 1004 were characterized by increased levels of alanine, GABA, glutamate, phenylalanine, proline, serine, and threonine under hypoxia (Fig. 5b). In this context, GABA and alanine showed the highest accumulation among the amino acids. GABA had displayed an eightfold increase in clone VCC 975 and 12fold for clone VCC 1004. Moreover, alanine increased 14fold for clone VCC 975, and 73-fold for clone VCC 1004 (Fig. 5b). In addition, hypoxia caused an increase in aspartate and valine in the root of clone VCC 1004 but not in VCC 975 (Fig. 5b). Significant decreases in tyrosine levels were only observed in the root of clone VCC 975 under hypoxia. Glycine levels were unaltered by hypoxia in the roots of both clones. Interestingly, the levels of tricarboxylic acid (TCA) cycle intermediates such as citrate, isocitrate, 2-oxoglutarate, succinate, fumarate, and malate in shoots of VCC 975 and VCC 1004 under hypoxia conditions were similar to those of the control plants (Fig. 6a). Alternatively, levels of 2oxoglutarate were consistently reduced in the root of clone VCC 975, with no change in the roots of clone VCC 1004 (Fig. 6b). A significant decrease in citrate levels was only observed in the root of clone VCC 1004. Moreover, succinate displayed an increase of 2.5 -fold in roots of both clones in hypoxic conditions. There was no difference in the levels of isocitrate, fumarate, and malate both in the root of clone VCC 975 and VCC 1004 as compared with control plants (Fig. 6b). All the results about the metabolic profile were compared using the $t$ test with the relative values of the metabolites. There are also the absolute values of the metabolites (Supplementary Tables 1 and 2) and the two-way ANOVA to compare the interaction between the factors in the study (Supplementary material 2).

\section{Discussion}

Our results demonstrated that despite shoot and root tissues displaying changes in phytohormone concentrations and growth elicited by $\mathrm{O}_{2}$ deprivation, the shoots of these clones did not display differences in growth and primary metabolism. This finding suggests that Eucalyptus clones primarily respond to $\mathrm{O}_{2}$ deprivation in below-ground tissues or that primary metabolism is more resilient than those in the heterotrophic organs. Either way, our findings highlight that hypoxia elicits chemical responses in below-ground tissues that signify responses to either avoid or mitigate such conditions.

Roots of clone VCC 1004 contained higher concentrations of ACC in leaves compared to clone VCC 975 (Figs 3 and 4). It is known that oxygen deficiency stimulates ACC synthase in roots (Peng et al. 2005; Van de Poel and Van Der Straeten 2014) which may be transported to the leaves via the transpiration stream. In this context, a significant increase in the ACC 


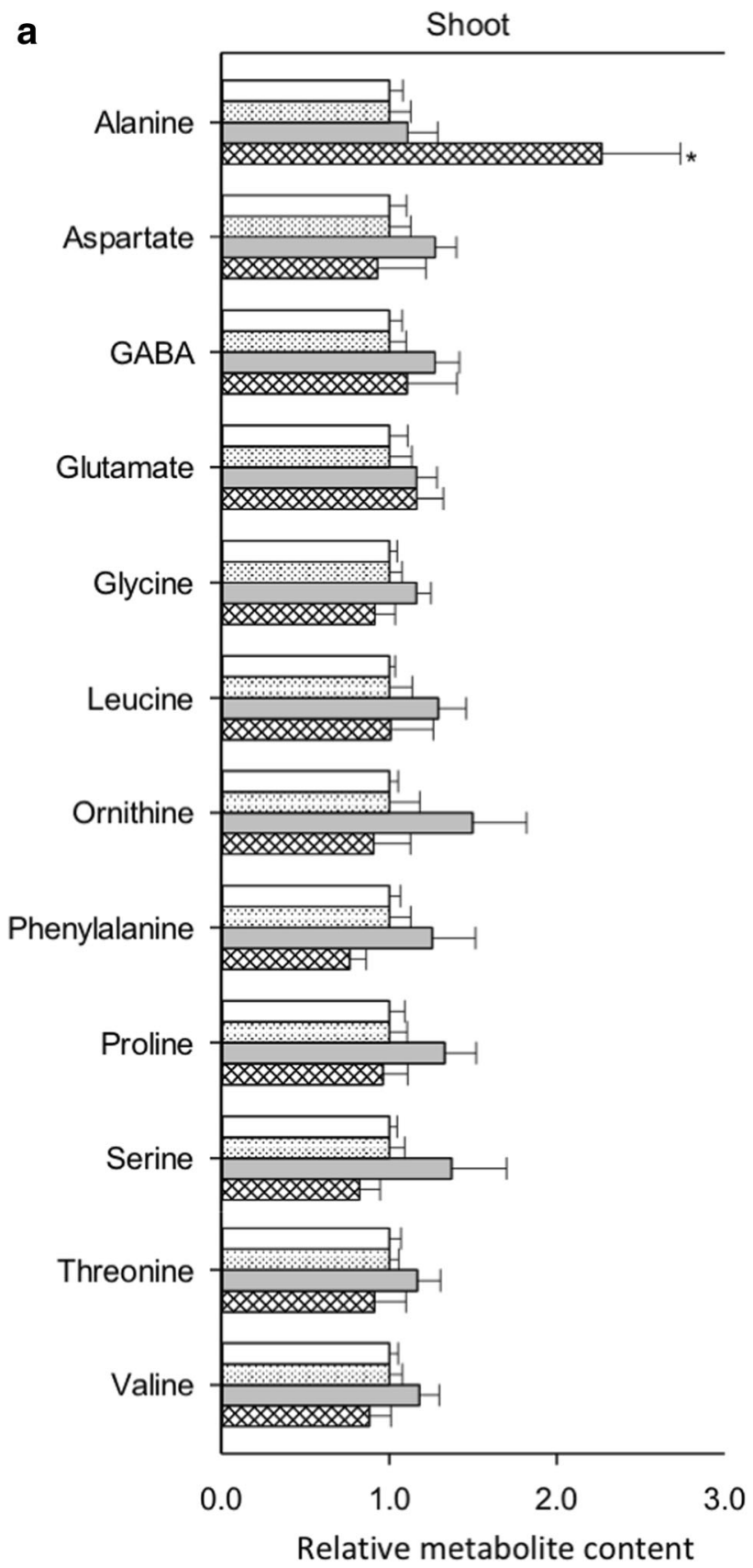

Fig. 5 Changes in metabolite profiles in the a shoot and $\mathbf{b}$ root of Eucalyptus clones under hypoxic conditions. Data are normalized with respect to mean responses calculated for the control treatment in each organ. Asterisks indicate values determined by the Student's $t$ test to be

concentration was observed in the root of both clones under hypoxia (Figs 3 and 4). However, hypoxia led to an increase in the ACC concentration only in leaves of clone VCC 1004. Equally, the roots of both clones had the same increase in ethylene production under hypoxia (Fig. 4). It is commonly observed that the genes responsible for ethylene biosynthesis are upregulated during hypoxic stress (Peng et al. 2005), where ethylene acts as a regulator of root morphology. It is likely that the most important responses of the root system to

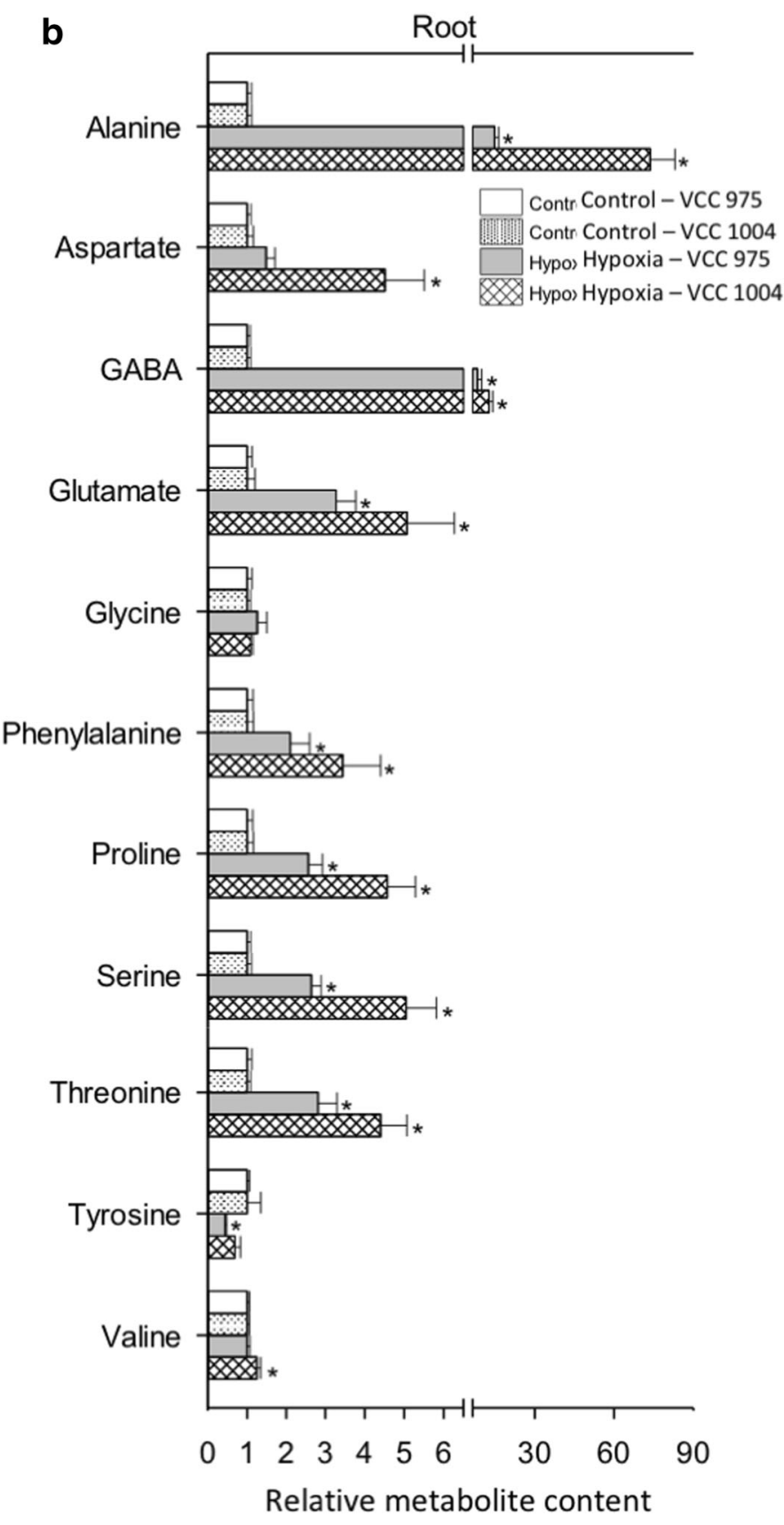

significantly different from control $(P<0.05)$. Values are presented as means of six replicates \pm standard error. The full dataset from the metabolite profiling study is available as Supplementary Tables S1, S2, $\mathrm{S} 3$, and S4

tolerate the prolonged hypoxia are the development of aerenchyma (and increased gas-filled porosity) and the formation of adventitious roots (Vidoz et al. 2010; Yukiyoshi and Karahara 2014). In addition to these anatomical and morphological changes, plant hormones also play a crucial role in eliciting chemical responses governing metabolism when the soil environment changes from aerated to hypoxic for short periods of time (Steffens and Sauter 2014). Increases in ethylene biosynthesis may also enhance root sensitivity to endogenous 
Fig. 6 Changes in tricarboxylic acid cycle intermediates in a shoot and b root of Eucalyptus clones under hypoxic conditions. Data are normalized with respect to a mean response calculated for the control treatment in each organ. Asterisks indicate values determined by the Student's $t$ test to be significantly different from control $(P<0.05)$. Values are presented as means of six replicates \pm standard error. The full dataset from the metabolite profiling study is available as Supplementary Tables S1, S2, S3, and S4

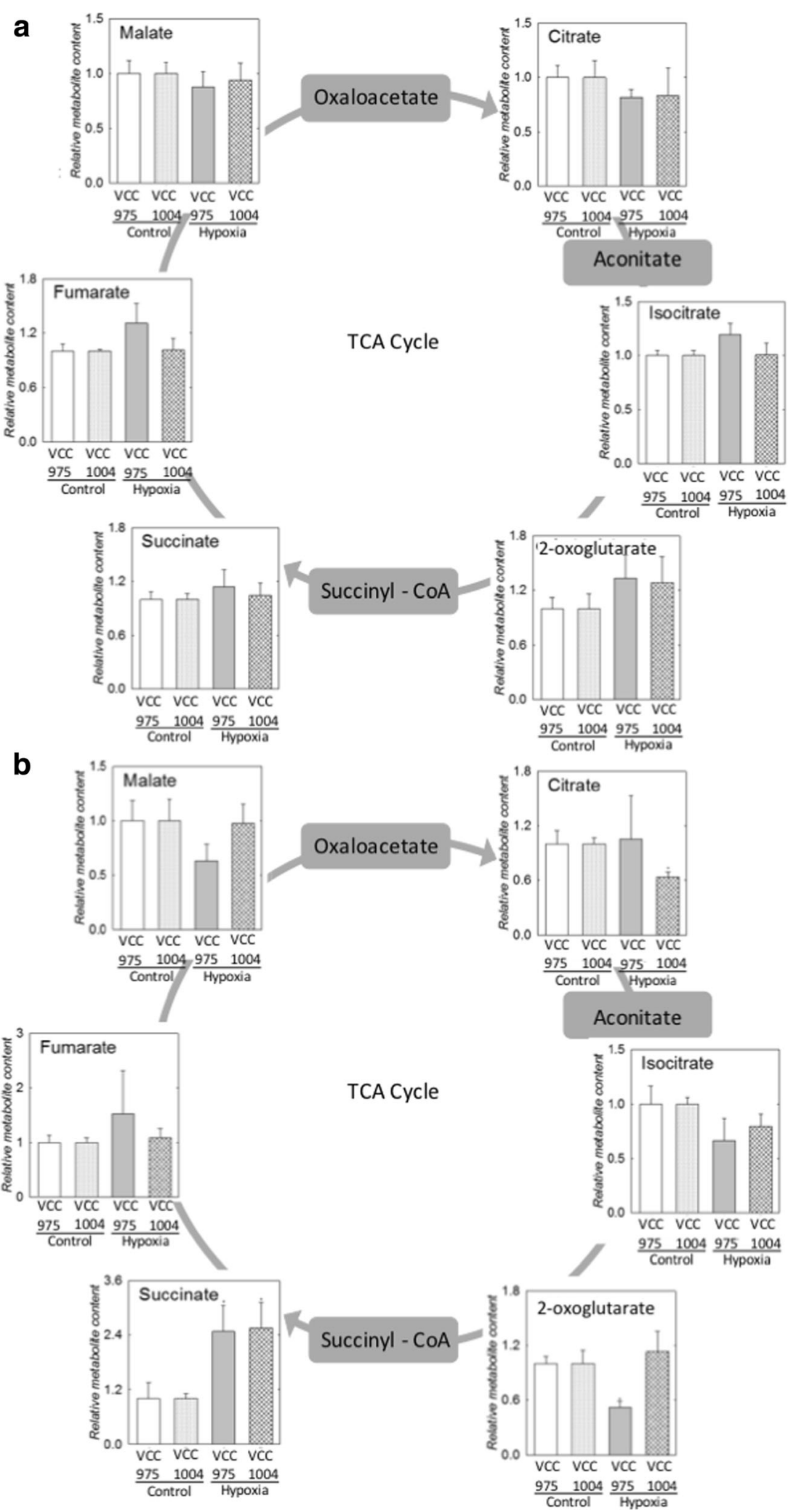

auxin promoting the formation of adventitious roots (Steffens and Rasmussen 2016). In this context, it was surprising that the hypoxia reduced the concentration of IAA in roots (Fig. 4). Auxins are well known to affect root growth by inducing cell division and/or expansion (Wang and Ruan 2013); however, we observed that hypoxia negatively affected the accumulation of IAA in roots of clones VCC 975 and VCC 1004, while it remained unchanged in the shoot of both clones (Figs 2 and 
4). Our results indicate an absence of a detectable auxin response suggesting the threshold of treatment intensity or longevity was not reached to elicit a change in auxin concentrations among autotrophic organs.

ABA is associated with many developmental and physiological processes in plants including responses in stomatal regulation (Zou et al. 2015). Our results demonstrated that levels of ABA were higher in the leaves of clone VCC 1004 in hypoxic conditions than leaves of clone VCC $975 . g_{\mathrm{s}}$ decreased more slowly in clone VCC 975 than in clone VCC 1004 under hypoxia, suggesting the well-established involvement of ABA in stomatal regulation. There is evidence that ABA also induces changes in leaf primary metabolism (Ibrahim and Jaafar 2013). This was not observed in the present study indicating that stomatal limitation is more influenced by ABA than primary metabolism. Even under hypoxic conditions, clone VCC 975 maintained the same $C_{\mathrm{i}}$ as that of plants in the aerated treatment. Under hypoxia, even with a lower $g_{\mathrm{s}}$ in the hypoxic condition, the clone VCC 1004 kept the same $A$ as VCC 975 causing a decrease in the $C_{\mathrm{i}} / C_{\mathrm{a}}$ ratio (Fig. 1). Decreases suffered in $A$ are reflected by decreases in $C_{\mathrm{i}} / C_{\mathrm{a}}$ values of clone VCC 1004 and as such may influence long-term leaf function and longevity compared to clone VCC 975. In agreement with this hypothesis, clone VCC 975 exhibited higher growth than clone VCC 1004 under hypoxia (Fig. S2) thus, the effects of hypoxia in the roots and how they influence stomatal closure in each clone, may define the longterm tolerance to the stresses caused by hypoxia but is not the only factor responsible for the decrease in $A$.

In the roots, levels of succinate increased upon exposure to hypoxia in both clones (Fig. 6) while clone VCC 1004 had higher concentrations of sucrose in the root under hypoxia compared to clone VCC 975 (Table S4). This may result from a decreased consumption of these metabolites by respiration and fermentation. The concentrations of GABA significantly increased in the root of both clones, but not in the shoot (Fig. 6) suggesting an activation of GABA shunt in the root (Paul et al. 2016). Most amino acids under hypoxic conditions were higher in the roots for both clones. For example, alanine concentrations in the roots of both clones increased under hypoxic conditions. Alanine and GABA can act as a carbon storage in stress periods and act to maintain the TCA cycle activity (Rocha et al. 2010; Renault et al. 2013). However, an alternative non-cyclic pathway from alanine and GABA to succinate exists and can regenerate the succinate using reducing power (NADH) in hypoxic and anoxic stresses (Rocha et al. 2010; Michaeli et al. 2011). The fact that one of the clones, VCC 1004, was shown to display an enhanced alanine concentration in the shoot and in the root while the concentration of alanine remained unchanged among the other clones (Fig. 5) suggests that alanine concentration in the shoot is unlikely to be greatly influenced by the root. Taken together, our observations indicate that alanine concentrations and
GABA shunt may be an important characteristic to improve the physiological activity of Eucalyptus seedlings under hypoxia.

Under hypoxia, pyruvate is partitioned to supply fermentation processes leading to a decrease in the TCA cycle activity (Bailey-Serres et al. 2012). In the present study, an increase in the succinate levels was seen in response to hypoxia in roots of both clones (Fig. 6). Succinate is accumulated due to the reduced activity of mitochondrial succinate dehydrogenase when the lack of oxygen inhibits electron transport at cytochrome $c$ oxidase (Branco-Price et al. 2008). Nevertheless, succinate levels may play an important role to ameliorate the effects of lack of oxygen (Branco-Price et al. 2008). Although no differences in the succinate concentration were detected between the root of the two clones, their metabolic profiles were clearly distinctive. For example, the concentration of amino acids derived from glycolytic intermediates (e.g., alanine, phenylalanine, serine, and valine) increased more slowly in the root of clone VCC 975 than VCC 1004. Furthermore, the pool size of amino acids such as aspartate, glutamate, proline, and threonine was lower in the root of clone VCC 975 than in clone VCC 1004 under hypoxia conditions (Fig. 5). The reduced pool size of the amino acids observed in the root of clone VCC 975 indicates that amino acids are being utilized more rapidly when the plant is grown under hypoxia. 2-Oxoglutarate is a central metabolite in the TCA cycle and it is an integration point of carbon and nitrogen metabolism (Araújo et al. 2014). The concentration of 2oxoglutarate decreased consistently only in the root of clone VCC 975 (Fig. 6). Together, this indicates that clone VCC 975 has a more flexible metabolism than clone VCC 1004 under hypoxia. This reflects a phenotypic difference between clone VCC 975 and clone VCC 1004 under hypoxia in the field (Fig. S2) suggesting that such properties may be of interest to selection programs for site-specific, breeding purposes.

\section{Conclusion}

Our results demonstrate that Eucalyptus clones VCC 975 and VCC1004 are able to adjust to short-term hypoxia by reconfiguration of central metabolic processes in roots such as TCA cycle and amino acid metabolism. The enhanced production of hormones is likely required to optimize metabolic performance in the roots of Eucalyptus clones under hypoxia. Despite aerial tissues of Eucalyptus clones displaying alteration in hormone concentrations, shoot metabolism is not affected by short-term hypoxia. However, interactions of stomatal regulation with metabolic activity in the root are seemingly essential. While the functional relationships between the measured metabolites remain to be fully characterized, our study has shown that selected metabolites, targeted on the basis of 
known processes of plant function, may be used for the early detection of hypoxic stress.

Acknowledgments Discussions with Professor Timothy Colmer (University of Western Australia) were highly valuable in the development of this work. My gratitude is also extended to the NUBIOMOL (Núcleo de Análises de Biomoléculas) for the support with the LC-MS analysis.

Funding EFM would like to thank CAPES (Coordination of Personal Improvement at the Higher Level) and $\mathrm{CNPq}$ (Brazilian Council for Advancement of Science and Technology) for the financial support.

\section{Compliance with ethical standards}

Conflict of interest The authors declare that they have no conflicts of interest.

\section{References}

Abraf, Anuário Estatístico da Abraf (2013) Ano base 2012. Associação Brasileira de Produtores de Florestas Plantadas, Brasília, 2012.148 p

Araújo WL, Martins AO, Fernie AR, Tohge T (2014) 2-Oxoglutarate: linking TCA cycle function with amino acid, glucosinolate, flavonoid, alkaloid, and gibberellin biosynthesis. Front Plant Sci 5:552

Argus RE, Colmer TD, Grierson PF (2015) Early physiological flood tolerance is followed by slow post-flooding root recovery in the dryland riparian tree Eucalyptus camaldulensis subsp. Refulgens. Plant Cell Environ 38:1189-1199. https://doi.org/10.1111/pce. 12473

Bai T, Yin R, Li C, Ma F, Yue Z, Shu H (2011) Comparative analysis of endogenous hormones in leaves and roots of two contrasting Malus species in response to hypoxia stress. J Plant Growth Regul 30:119 127. https://doi.org/10.1007/s00344-010-9173-9

Bailey-Serres J, Voesenek LACJ (2008) Flooding stress: acclimations and genetic diversity. Annu Rev Plant Biol 59:313-339. https://doi.org/ 10.1146/annurev.arplant.59.032607.092752

Bailey-Serres J, Fukao T, Gibbs DJ, Holdsworth MJ, Lee SC, Licausi F, Perata P, LACJ V, van Dongen JT (2012) Making sense of low oxygen sensing. Trends Plant Sci 17(3):129-138. https://doi.org/ 10.1016/j.tplants.2011.12.004

Beckman TG, Perry RL, Flore JA (1992) Short-term flooding affects gas exchange characteristics of containerized sour cherry trees. HortScience 27:1297-1301 http://hortsci.ashspublications.org/ content/27/12/1297.short

Bison O, Ramalho MAP, Rezende GDSP, Rezende MDV (2006) Comparison between open pollinated progenies and hybrids performance in Eucalyptus grandis and Eucalyptus urophylla. Silvae Genet 55(4/5):192-196. https://doi.org/10.1515/sg-2006-0026

Branco-Price C, Kaiser KA, Jang CJH, Larive CK, Bailey-Serres J (2008) Selective mRNA translation coordinates energetic and metabolic adjustments to cellular oxygen deprivation and reoxygenation in Arabidopsis thaliana. Plant J 56:743-755. https://doi.org/10.1111/ j.1365-313X.2008.03642.x

Cao WH, Liu J, He XJ, Mu RL, Zhou HL, Chen SY, Zhang JS (2007) Modulation of ethylene responses affects plant salt-stress responses. Plant Physiol 143:707-719. https://doi.org/10.1104/pp.106.094292

Clark R (1975) Characterization of phosphatase of intact maize roots. J Agric Food Chem 23:458-460. https://doi.org/10.1021/ jf60199a002
Colmer TD, Voesenek LACJ (2009) Flooding tolerance: suites of plant traits in variable environments. Funct Plant Biol 36:665-681. https://doi.org/10.1071/FP09144

Dethloff F, Erban A, Orf I, Alpers J, Fehrle I, Beine-Golovchuk O, Schmidt S, Schwachtje J, Kopka J (2014) Profiling methods to identify cold-regulated primary metabolites using gas chromatography coupled to mass spectrometry. Method Mol Biol 1166:171-197. https://doi.org/10.1007/978-1-4939-0844-8 14

Dreyer E (1994) Compared sensitivity of seedlings from 3 woody species (Quercus robur L., Quercus rubra L and Fagus sylvatica L.) to waterlogging and associated root hypoxia: effects on water relations and photosynthesis. Ann For Sci 51:417-429. https://doi.org/10. 1051/forest: 19940407

Feng X, Porporato A, Rodriguez-Iturbe I (2013) Changes in rainfall seasonality in the tropics. Nat Clim Chang 3(9):811-815. https://doi. org/10.1038/nclimate1907

Geisler-Lee J, Caldwell C, Gallie DR (2010) Expression of the ethylene biosynthetic machinery in maize roots is regulated in response to hypoxia. J Exp Bot 61:857-871. https://doi.org/10.1093/jxb/erp362

Genty B, Briantais JM, Baker NR (1989) The relationship between the quantum yield of photosynthetic electron transport and quenching of chlorophyll fluorescence. Biochim Biophys Acta Gen Subj 990(1): 87-92. https://doi.org/10.1016/S0304-4165(89)80016-9

Gonçalves JLM, Alvares CA, Souza AHBN, Arthur Junior JC (2016) Caracterização edafoclimática e manejo de solos das áreas com plantações de eucalipto. In: Schumacher MV, Viera M, organizadores. Silvicult Euc Brasil. Santa Maria: Editora UFSM; p.111-54

Graf A, Schlereth A, Stitt M, Smith AM (2010) Circadian control of carbohydrate availability for growth in Arabidopsis plants at night. Proc Natl Acad Sci U S A 107:9458-9463. https://doi.org/10.1073/ pnas.0914299107

Harguindeguy I, Castro GF, Novais SV, Vergutz L, Araujo WL, Novais RF (2017) Physiological responses to hypoxia and manganese in Eucalyptus clones with differential tolerance to Vale do Rio Doce shoot dieback. Rev Bras Cienc Solo 41:e0160550. https://doi.org/ 10.1590/18069657rbes20160550

Harrington JT, Mexal JG, Fisher JT (1994) Volume displacement provides a quick and accurate way to quantify new root production. Tree Plant Notes 45:121-124

Ibrahim MH, Jaafar HZE (2013) Abscisic acid induced changes in production of primary and secondary metabolites, photosynthetic capacity, antioxidant capability, antioxidant enzymes and lipoxygenase inhibitory activity of Orthosiphon stamineus Benth. Molecules 18:7957-7976. https://doi.org/10.3390/ molecules 18077957

Indústria brasileira de árvores. Iba 2014. http://www.iba.org/shared/iba 2014_pt.pdf

Kreuzwieser J, Rennenberg H (2014) Molecular and physiological responses of trees to waterlogging stress. Plant Cell Environ 37: 2245-2259. https://doi.org/10.1111/pce.12310

Leite FP, Novais RF, Silva IR, Barros NF, Neves JCL, Medeiros AGB, Ventrella MC, Villani EMA (2014) Manganese accumulation and its relation to "eucalyptus shoot blight in the Vale do Rio Doce". Rev Bras Cienc Solo 38:193-204. https://doi.org/10.1590/S010006832014000100019

Lisec J, Schauer N, Kopka J, Willmitzer L, Fernie AR (2006) Gas chromatography mass spectrometry-based metabolite profiling in plants. Nat Protoc 1:387-396. https://doi.org/10.1038/nprot.2006.59

Loreti E, van Veen H, Perata P (2016) Plant responses to flooding stress. Curr Opin Plant Biol 33:64-71. https://doi.org/10.1016/j.pbi.2016. 06.005

Luedemann A, Strassburg K, Erban A, Kopka J (2008) TagFinder for the quantitative analysis of gas chromatography-mass spectrometry (GC-MS)-based metabolite profiling experiments. Bioinformatics 24(5):732-737. https://doi.org/10.1093/bioinformatics/btn023 
Mergemann H, Sauter M (2000) Ethylene induces epidermal cell death at the site of adventitious root emergence in rice. Plant Physiol 124(2): 609-614. https://doi.org/10.1104/pp.124.2.609

Michaeli S, Fait A, Lagor K, Nunes-Nesi A, Grillich N, Yellin A, Bar D, Khan M, Fernie AR, Turano FJ, Fromm H (2011) A mitochondrial GABA permease connects the GABA shunt and the TCA cycle, and is essential for normal carbon metabolism. Plant J 67(3):485-498. https://doi.org/10.1111/j.1365-313X.2011.04612.x

Müller M, Munné-Bosch S (2011) Rapid and sensitive hormonal profiling of complex plant samples by liquid chromatography coupled to electrospray ionization tandem mass spectrometry. Plant Methods 7(1):37. https://doi.org/10.1186/1746-4811-7-37

National Register of Cultivars Website: http://sistemas.agricultura.gov.br/ snpc/cultivarweb/cultivares_registradas.php

Paul MV, Iyer S, Amerhauser C, Lehmann M, van Dongen JT, Geigenberger P (2016) Oxygen sensing via the ethylene response transcription factor RAP2.12 affects plant metabolism and performance under both normoxia and hypoxia. Plant Physiol 172:141153. https://doi.org/10.1104/pp.16.00460

Peng HP, Lin TY, Wang NN, Shih MC (2005) Differential expression of genes encoding 1-aminocyclopropane-1-carboxylate synthase in Arabidopsis during hypoxia. Plant Mol Biol 58:15-25. https://doi. org/10.1007/s11103-005-3573-4

Pierik R, Sasidharan R, Voesenek LACJ (2007) Growth control by ethylene: adjusting phenotypes to the environment. J Plant Growth Regul 26(2):188-200. https://doi.org/10.1007/s00344-006-0124-4

Renault H, El Amrani A, Berger A, Mouille G, Soubigou-TaconnaT L, Bouchereau A, Deleu C (2013) $\gamma$-Aminobutyric acid transaminase deficiency impairs central carbon metabolism and leads to cell wall defects during salt stress in Arabidopsis roots. Plant Cell Environ 36(5):1009-1018. https://doi.org/10.1111/pce.12033

Rocha M, Licausi F, Araújo WL, Nunes-Nesi A, Sodek L, Fernie AR, van Dongen JT (2010) Glycolysis and the tricarboxylic acid cycle are linked by alanine aminotransferase during hypoxia induced by waterlogging of Lotus japonicus. Plant Physiol 152(3):1501-1513. https://doi.org/10.1104/pp.109.150045

Rockwood DL, Rudie AW, Ralph SA, Zhu JY, Winandy JE (2008) Energy product options for eucalyptus species grown as short rotation woody crops. Int J Mol Sci 9(8):1361-1378. https://doi.org/10. 3390/ijms9081361

Silva PO, Medina EF, Barros RS, Ribeiro DM (2014) Germination of salt-stressed seeds as related to the ethylene biosynthesis ability in three Stylosanthes species. J Plant Physiol 171(1):14-22. https://doi. org/10.1016/j.jplph.2013.09.004

Steffens B, Rasmussen A (2016) The physiology of adventitious roots. Plant Physiol 170(2):603-617. https://doi.org/10.1104/pp.15.01360

Steffens B, Sauter M (2009) Epidermal cell death in rice is confined to cells with a distinct molecular identity and is mediated by ethylene and $\mathrm{H} 2 \mathrm{O} 2$ through an autoamplified signal pathway. Plant Cell 21: 184-196. https://doi.org/10.1105/tpc.108.061887

Steffens B, Sauter M (2014) Role of ethylene and other plant hormones in orchestrating the responses to low oxygen conditions. Plant Cell Monographs 21:117-132. https://doi.org/10.1007/978-3-70911254-0 7

Steffens B, Steffen-Heins A, Sauter M (2013) Reactive oxygen species mediate growth and death in submerged plants. Front Plant Sci 4: 179. https://doi.org/10.3389/fpls.2013.00179

Sulpice R, Flis A, Ivakov AA, Apelt F, Krohn N, Encke B, Abel C, Feil R, Lunn JE, Stitt M (2014) Arabidopsis coordinates the diurnal regulation of carbon allocation and growth across a wide range of photoperiods. Mol Plant 7(1):137-155. https://doi.org/10.1093/mp/ sst127

Van de Poel B, Van Der Straeten D (2014) 1-aminocyclopropane-1carboxylic acid (ACC) in plants: more than just the precursor of ethylene! Front Plant Sci 5:640. https://doi.org/10.3389/fpls.2014. 00640

Vartapetian BB, Jackson MB (1997) Plant adaptations to anaerobic stress. Ann Bot 79:3-20. https://doi.org/10.1093/oxfordjournals.aob. a010303

Vidoz ML, Loreti E, Mensuali A, Alpi A, Perata P (2010) Hormonal interplay during adventitious root formation in flooded tomato plants. Plant J 63:551-562. https://doi.org/10.1111/j.1365-313X. 2010.04262.x

Voesenek LACJ, Bailey-Serres J (2015) Flood adaptive traits and processes: an overview. New Phytol 206:57-73. https://doi.org/10. 1111/nph.13209

Voesenek LACJ, Banga M, Thier RH, Mudde CM, Harren FJM, Barendse GWM, Blom CWPM (1993) Submergence-induced ethylene synthesis, entrapment, and growth in two plant species with contrasting flooding resistances. Plant Physiol 103(3):783-790. https://doi.org/10.1104/pp.103.3.783

Wang L, Ruan YL (2013) Regulation of cell division and expansion by sugar and auxin signaling. Front Plant Sci 4:163. https://doi.org/10. 3389/fpls.2013.00163

Yamauchi T, Watanabe K, Fukazawa A, Mori H, Abe F, Kawaguchi K, Oyanagi A, Nakazono M (2013) Ethylene and reactive oxygen species are involved in root aerenchyma formation and adaptation of wheat seedlings to oxygen-deficient conditions. J Exp Bot 65(1): 261-273. https://doi.org/10.1093/jxb/ert371

Yukiyoshi K, Karahara I (2014) Role of ethylene signalling in the formation of constitutive aerenchyma in primary roots of rice. AoB Plants 6:plu043. https://doi.org/10.1093/aobpla/plu043

Zou J, Li X, Ratnasekera D, Wang C, Liu W, Song L, Zhang W, Wu W (2015) Arabidopsis calcium-dependent protein kinase8 and catalase 3 function in abscisic acid-mediated signaling and $\mathrm{H} 2 \mathrm{O} 2$ homeostasis in stomatal guard cells under drought stress. Plant Cell 27(5):1445-1460. https://doi.org/10.1105/tpc.15.00144

\section{Affiliations}

\section{Eduardo F. Medina ${ }^{1}$ (D) - Gustavo C. V. Mayrink ${ }^{1} \cdot$ Cleide R. Dias $^{2} \cdot$ Camilo E. Vital $^{3} \cdot$ Dimas M. Ribeiro $^{4} \cdot$ Ivo R. Silva $^{1}$ • Andrew Merchant ${ }^{5}$}

1 Departamento de Solos e Nutrição de Plantas, Universidade Federal de Viçosa, Viçosa, MG 36570-000, Brazil

2 Departamento de Entomologia, Universidade Federal de Viçosa, Viçosa, Brazil

3 Núcleo de Análises de Biomoléculas, Viçosa, Brazil
4 Departamento de Biologia Vegetal, Universidade Federal de Viçosa, Viçosa, Brazil

5 Faculty of Science, The University of Sydney, Sydney, Australia 